\section{Electrochemical impedance and potentio-dynamic polarization of construction steel in cement extract, containing red mud and chloride contamination}

D.A.Koleva ${ }^{1}$, O.Copuroglu ${ }^{1}$, K.van Breugel ${ }^{1}$, J.H.W.de Wit ${ }^{2}$

${ }^{1,2}$ Delft U-ty of Technology, The Netherlands, ${ }^{1}$ Faculty Civil Eng. \& Geosciences, Dep. Mater. Sci., Stevinweg 1, 2628 CN Delft;

${ }^{2}$ Faculty $3 \mathrm{mE}$, Dep. Mater. Sci.\&Eng., Mekelweg 2, 2628 CD Delft

This work presents a preliminary study on the corrosion behavior of construction steel in cement-based materials, containing waste products, namely "red mud", as partial replacement of the cement portion in the mixtures. The paper reports on the initial electrochemical tests in model solutions of cement extract $(\mathrm{CEm})$, cement extract + $20 \%$ red mud (CEmRM) and chloride contaminated (adding $5 \% \mathrm{NaCl}$ ) solutions (CEmN and $\mathrm{CEmRMN}$ ), thus aiming to study the behavior of the steel electrodes in such media, prior to the tests in mortar and concrete.

"Red mud" is the waste, generated during aluminum production from bauxite. It is reported that the annual production of 1 tone of metallic aluminum generates about 2 tones of red mud. Consequently, research on ways of making use of this residue is of significant importance. Moreover, in addition to the economic and ecological advantages, the use of "red mud" will not create new residues.

Materials: Steel electrodes (construction steel FeB500HWL) of $4 \mathrm{~cm}^{2}$ exposed surface were immersed in the above described solutions and monitored at different intervals. The solutions were prepared as follows: cement extract $(\mathrm{CEm})$ by mixing water and Portland cement (OPC CEM 32.5), ratio $1: 1$, stirring for $24 \mathrm{~h}$ and filtration; cement extract + red mud $(\mathrm{CEmRM}): \mathrm{CEm}+20 \%$ replacement of the cement portion with dry powder $\left(105^{\circ} \mathrm{C}\right)$ of red mud; chloride containing solutions: by adding $5 \% \mathrm{NaCl}$ to the already filtrated CEm and CEmRM. The red mud compositions, determined by XRF and the cement composition are given in Table 1 .

\begin{tabular}{|c|c|c|c|c|c|}
\hline \multicolumn{3}{|c|}{ Red mud (XRF) } & \multicolumn{2}{|c|}{ OPC CEMI 32.5) } & Experimental methods: \\
\hline $\mathrm{Z}$ & wt. $\%$ & StdErr & StdComp & Wt. \% & Elecrochem. impedance \\
\hline $\mathrm{Na}_{2} \mathrm{O}$ & 14.25 & 0.39 & $\mathrm{Na}_{2} \mathrm{O}$ & 0.24 & $\mathrm{am}$ \\
\hline $\mathrm{MgO}$ & 0.124 & 0.014 & $\mathrm{MgO}$ & 2.00 & \\
\hline $\mathrm{Al}_{2} \mathrm{O}_{3}$ & 29.10 & 0.30 & $\mathrm{Al}_{2} \mathrm{O}_{3}$ & 5.03 & l \\
\hline $\mathrm{SiO}_{2}$ & 20.24 & 0.45 & $\mathrm{SiO}_{2}$ & 21.00 & before and after \\
\hline $\mathrm{P}_{2} \mathrm{O}_{5}$ & 0.155 & 0.003 & $\mathrm{P}_{2} \mathrm{O}_{5}$ & 0.16 & for defining \\
\hline $\mathrm{SO}_{3}$ & 0.525 & 0.058 & $\mathrm{SO}_{\mathrm{Z}}$ & 3.00 & \\
\hline $\mathrm{Cl}$ & 0.142 & 0.016 & $\mathrm{Mn}_{2} \mathrm{O}_{5}$ & 0.06 & \\
\hline $\mathrm{K}_{2} \mathrm{O}$ & 0.118 & 0.013 & & 0.65 & composition of the produ \\
\hline $\mathrm{CaO}$ & 3.54 & 0.21 & $\mathrm{CaO}$ & 63.90 & \\
\hline $\mathrm{TiO}_{2}$ & 6.2 & 0.27 & $\mathrm{TiO}$ & 0.30 & \\
\hline $\mathrm{Fe}_{2} \mathrm{O}_{3}$ & 24.85 & 0.48 & $\mathrm{Fe}_{2} \mathrm{O}_{3}$ & 2.83 & areby nr \\
\hline
\end{tabular}

are the recorded responses from PDP and EIS after $45 \mathrm{~min}$, 3 days and 11 days of immersion (the latter only for chloride containing solutions).
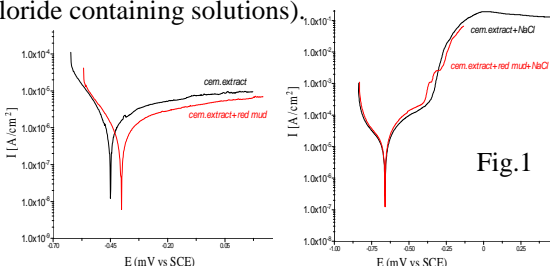

The $\mathrm{pH}$ of all solutions is in the range of 12.9 to 13.2 , therefore passivity of the steel surface is expected in CEm and CEmRM and localized corrosion in the chloride containing solutions CEmN and CEmRMN. Fig.1 presents the PDP curves in CEm and CEmRM (left) and the chloride containing solutions (right) after $45 \mathrm{~min}$ (i.e. after OCP stabilization). Although similar behavior is observed, the corrosion current density and anodic current for the steel surface in solutions containing red mud is lower, compared to cement extract only. In chloride containing solutions after $45 \mathrm{~min}$ immersion the behavior in both solutions is similar. Further, the above described electrochemical behavior maintains similar trends for longer immersion time. The corrosion behavior of the steel electrodes after 11 days of immersion in the Cl-containing solutions already differs significantly, exhibiting much higher current densities for $\mathrm{CEmN}$ and significantly better corrosion resistance in the CEmRMN solution, containing red mud (Fig.2 right). EIS measurements support the PDP tests (Fig.3). The Rp values, derived from PDP tests are given in Table 2.
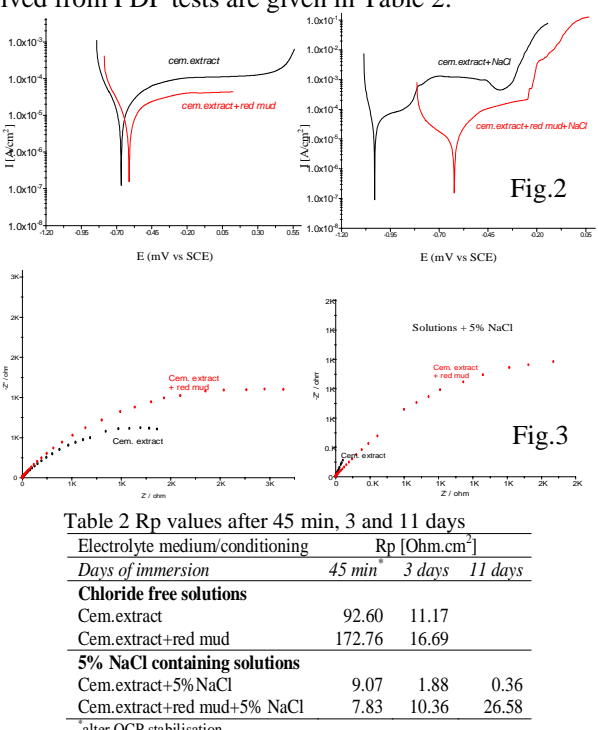

Morphology and composition of the product layers on the steel surface was investigated by SEM and EDX (only morphology presented here). Fig.4 presents the "as received" steel surface (a); steel surface after 11 days immersion in CEm (b) and CEmRM (c); steel surface after 11 days immersion in the chloride containing solutions of CEmN (d) and CEmRMN (e). Fig.4b visualizes the typical morphology of a product layer, formed in cement extract (e.g. well crystallized ettringite); Fig.4c depicts the adhered red mud particles. Fig. $4 d$ reveals the significant amount of corrosion damage after 11 days immersion in CEmN $(5 \%$ $\mathrm{NaCl}$ ), while for the specimens, immersed in the same solution, but with red mud addition (CEmRMN), the corrosion damage and deposited amounts of corrosion products are significantly lower.



In conclusion, the preliminary tests on the electrochemical behavior of construction steel in chloride free and chloride containing cement extract with and without "red mud" additions show the positive influence of red mud in terms of increased corrosion resistance. This positive effect of red mud addition to cement extract, especially in the presence of chlorides, is most likely denoted to the adherence of the red mud particles on the steel surface, their further recrystallization with potential cycling and thus hindering the steel dissolution. Consequently, "red mud" addition to reinforced mortar (concrete) will most likely lead to increased corrosion resistance of the embedded steel, especially in chloride containing environment. 